\title{
ADVERTISING CREDIBILITY ACROSS DIFFERENT MEDIA CHANNELS
}

\author{
Lucia Vilčeková ${ }^{1}$ \\ 1Dr., Comenius University in Bratislava, SLOVAKIA, lucia.vilcekova@fm.uniba.sk
}

\begin{abstract}
In the field of communication, researchers are primarily interested in finding out about people's choices of media such as television, newspapers, magazines, online news, etc. Perceptions of the reliability and trustworthiness may be significantly affected by the selection of information sources and credibility can be suggested as one of the factors driving the traffic of individuals to certain media. The concept of credibility is not new and has been studied in the ancient Greece - how the speakers persuade audience members. However, studies of the credibility of mass media began interesting in times when the rising number of people started turning to radio for news instead of newspapers. Another change was brought by television and in the last decade of the 20th century, rise of the Internet has led to recent credibility studies comparing traditional sources with this emerging medium.

The purpose of this paper is to examine the differences in advertising credibility perception across different media channels - television, newspapers and the Internet and determine if the medium of delivery has an impact on credibility assessment of advertising. The results showed overall moderate credibility of all the media but newspapers have shown the highest overall credibility, followed by the Internet and television, respectively. Advertising credibility was higher in traditional media than in the Internet. Negative attitudes were the highest in the online channels and the most credible advertising channel was the television. The results indicated there is no relationship between the medium credibility and credibility of advertising. Communication to audiences requires an exploration of trustworthiness in order to formulate correct strategies. By recognizing the credibility of the advertisements and the media in which they are placed, the findings can be considered for attracting audiences.
\end{abstract}

Keywords: Advertising, credibility, media.

\section{LITERATURE REVIEW}

Communication theories stress the importance of audience perceptions of message source credibility in steering communication success. These principles are not only important elements for public speaking and interpersonal persuasion but are core constructs relevant to success in corporate and organizational communication, public relations, advertising, media and journalism. Audiences often dismiss „important messages as merely "spin" and accuse journalists of bias" and react to marketing and advertising as untrue or manipulative. Discussion of communication to audiences in today's society inherently requires an exploration of credulity, trustworthiness and issues of integrity (Chandler, 2013). 
Nowadays, people have a vast choice of information sources. But in many cases, certain information appears to be "better," or "more trustworthy" than other information. The challenge that most people then face is to judge which information is the more credible (Hilligoss and Soo Yung, 2008, p. 1475). O'Keefe (1990, p. 133) defined credibility as "judgments made by a perceiver (e.g., a message recipient) concerning the believability of a communicator". Wathen and Burkell (2002, p. 135) define credibility as 'believability'. In general, credible information sources may be described as trustworthy and therefore credibility is closely related to a general concept of trust.

Advertising credibility can be defined as the "extent to which the consumer perceives claims made about the brand in the ad to be truthful and believable" (MacKenzie and Lutz, 1989, p. 49). There are a number of factors that influence the consumer's attitude towards advertising such as target characteristics, source characteristics, message characteristics, cultural aspects, economical aspects, media characteristics, creativity and cognitive routes (Indu and Jagathy, 2012, p. 18).

According to Blackshaw (2008, p. 51), credibility is the product of six core drivers:

Trust - perhaps the most imperative factor of credibility. It consists of assurance, reliability, and belief.

- Authenticity requires being genuine, sincere, consistent and reliable. It is particularly important element of credibility in the age of the Internet, because audiences have additional tools to see the truth and fallacy.

- Transparency is when a company communicates openly information and data. This involves openness and visibility.

- Listening $s$ the degree to which a company invites open conversation, is approachable, and easy to reach.

- Responsiveness deals with companies reacting to, tackling and managing specific consumer interactions. In responsiveness, consumers see the eye of sincerity and genuine concern or appreciation for their problems or suggestions.

- Affirmation is a collective assertion of the "truth". It is a core credibility driver because truth, in the eyes of a growing number of consumers and buyers, is defined as the collective judgment of either peers or other consumers.

Advertisements play a major role in changing the perception and consumption pattern of the society in general. Many previous studies have already proved the link between the perception of an advertisement and the attitude and behaviour towards a product (Indu and Jagathy, 2012, p. 19).

A study done by Ambler and Hollier (2004) concerning advertising and credibility found that the more extravagant advertisement was perceived, the persuasiveness of that advertisement improved significantly as well as perceptions of the brand's quality.

Perceptions of the reliability and trustworthiness may be significantly affected by the selection of information sources. In particular, the significance of these criteria is emphasized when information seekers encounter conflicting information. In these situations, they have to assess the credibility and cognitive authority of alternative sources (Savolainen, 2007).

The readers control advertising exposure in the print media. They choose the pace, and decide how much time they spend looking at an ad because they may simply turn the page. According to Metha and Purvis (1995), it appears that one of the factors that influences how much attention will be paid to an ad is the attitude towards advertising in general.

\section{RESEARCH METHODS}

The sample of this study consists of 560 Slovak respondents and they were chosen on principles of convenience sampling. It is non-probability sampling technique where subjects are selected because of their convenient accessibility and proximity to the researcher. It is fast, inexpensive and easy technique. Data was collected in Slovakia and the instrument for data collection was a questionnaire. To measure the perception of media, general characteristics like objectiveness, activity, intelligence, professionalism, etc. were examined: The characteristics were in form of adjectives and the respondents were asked to choose where their position lies, on a 7 point scale between two bipolar words. This method was used because semantic differentiation is a procedure that involves rather standard scaling practices and offers a variety of analytical methods. Furthermore, five-point Likert-type statements were used to measure the degree which a person believes that advertising in given media (TV, the Internet and radio) is plausible and convincing. The items are general enough so that they can refer advertising in general or to advertising on a specific medium. The 
same type of scale was used to measure the general credibility of each medium. To be able to describe what makes advertising trustworthy, respondents were presented an open-ended question "What are the characteristics of a credible ad?".

The data was evaluated in SPSS, software for statistical computing and graphics. By assigning a set of integer values, such as $+3,+2,+1,0,-1,-2,-3$, to the seven gradations of each bipolar scale, the responses could be quantified under the assumption of equal-appearing intervals. The Likert scales ranged from -2 (absolutely disagree) to +2 (absolutely agree) and to summarize the results, calculation of the mean was used.

To examine, if there is any relationship between the medium credibility and credibility of advertising, Pearson Correlation was used. It is a technique to investigate the relationship between two quantitative variables, and Pearson's correlation coefficient $(r)$ measures the strength of the association between the two variables.

\section{RESEARCH RESULTS}

This study takes a broader perspective by looking at credibility of advertising across a range of media and examines if the credibility of concrete medium is correlated with credibility perception of advertising.

According to our research, following factors need to be considered. Weaknesses of the television are unprofessionalism, unfairness, low level of trustworthiness and relatively high-perceived political background and therefore easy manipulation and subjectivity of the news. The strongest attributes of TV are the presentation and ability to act fast. The strengths of the Internet are independence and high level of activity, whereas the weaknesses are low credibility and shallow coverage of the news. The best overall rating had the newspapers with the highest level of fairness, presentation, credibility and intelligent content. Nevertheless, the credibility of all the media was rather moderate. The newspapers have shown the highest overall credibility $(\mu=0.79)$, followed by the Internet $(\mu=0.67)$ and television $(\mu=0.61)$, respectively.

Attitudes toward advertising showed similar results. The overall credibility was moderate. Slovaks have shown scepticism toward all the forms of ads. The most credible advertising channel was television $(\mu=0.9)$, followed by newspapers $(\mu=0.78)$ and the negative attitudes were the highest in the online channels $(\mu=$ 0.62). In general, advertising credibility was higher in traditional media than in the Internet. According to the Slovaks, the most credible advertising form is word-of-mouth and it comes straight from the people who use the product or service. The branded websites are the second-most trusted format and on he third place are TV ads.

The factors that make an ad credible are depicting real-life situations, consumer experience, and real peoples' product and service recommendations. Consumers trust those ads that are truthful, honest and value-oriented. They should be meaningful, relevant and useful. The truth and honesty work for the consumer, not creativity or humour.

To examine, if there is any relationship between the medium credibility and credibility of advertising, Pearson Correlation was used. Critical value for given number of respondents and significance level of 0.05 is 0.088 . Comparison between credibility of television and credibility of TV ads indicate no association between these variables, Pearson's $r(560)=.08, p=0.7$. Further results indicated there is no relationship between the credibility of the Internet and credibility of online advertising, Pearson's $r(560)=-.066, p=0.56$. Newspapers credibility and perception of advertisement in the newspapers were not correlated, either, Pearson's $r(560)=$ $-.071, p=0.61$. Overall, there was no correlation between the medium credibility and credibility of advertising. The trust in specific medium does not have any influence on the credibility of advertising in the specific medium.

\section{DISCUSSION}

It is evident that credibility of the medium is not correlated with the credibility of advertising in the medium. What is important in advertisement perception is reality. Consumers trust those ads that are truthful, honest and value-oriented. The truth is important for the consumer - depicting real-life situations, consumer experience, and real peoples' product and service recommendations.

Credible stories beget good stories, and good stories shape perceptions and ultimately buyer behavior. Credibility rules the day - as Blackshaw (2008, p. 51) says. He defines six core elements of credibility that marketers must strive to achieve: trust, authenticity, transparency, listening, responsiveness, and affirmation. According to our study, the main drivers of advertising credibility are truth, customer experience and honesty.

Therefore, marketers should consider bringing truth and accuracy into advertising. Ads should inform, not entertain, and they should be meaningful, relevant and useful. Honesty should be a conscious choice to go 
beyond the scope of the consumer's explicit knowledge and present the company or brand as it is. Word-ofmouth is a very powerful tool to support honesty. Thanks to online media, the real story behind a brand and user experience is being spread with the added credibility of person-to-person communication. The real challenge in being honest lies in how brands choose to manage in a more transparent environment.

Today's consumers are demanding. They want to be in control. They need to feel respected and valued. For marketers, it is easy to achieve. Earning respect and credibility with consumers is simply showing they care. Being open for conversation, a comment, or feedback can improve the relationship.

\section{REFERENCE LIST}

Ambler, T., \& Hollier, E. (2004). The Waste in Advertising Is the Part That Works. Journal of Advertising Research, 44(4), 375-389.

Blackshaw, P. (2008). The six drivers of brand credibility. Marketing Management, 17(3), pp. 51-54.

Chandler, R. C. (2013). Director's Update: The Importance of Trust and Credibility in a Cynical and Skeptical Society. Retrieved from http://communication.cos.ucf.edu/june13-directors-update-2/

Hilligoss, B. \& Soo Yung, R. (2008). Developing a unifying framework of credibility assessment: Construct, heuristics, and interaction in context. Information Processing \& Management, 2008,44 (4), pp. 14711479.

Indu, R. \& Jagathy R. V. P. (2012). Developing a Theoretical Framework for a Study on the Impact of Advertising Credibility of Consumer Healthcare Products. European Journal of Commerce and Management Research, 1(1). pp. 14-24.

Mehta, A., \& Purvis, S. C. (1995, May). When attitudes towards advertising in general influence advertising success. In Conference of the American Academy of Advertising. Waco, TX: Baylor University, Norfolk, VA.

O'Keefe, D. J. (1990). Persuasion: Theory and Research. Newbury Park, CA: Sage.

Savolainen, R. Media credibility and cognitive authority. The case of seeking orienting information. Retrieved from http://InformationR.net/ir/12-3/paper319.html

Scott B. M. \& Lutz R. J. (1989). An Empirical Examination of Attitude Toward the Ad in an Advertising Pretest Context. Journal of Marketing, 53, pp. 48-65.

Wathen, C. N., \& Burkell, J. (2002). Believe it or not: Factors influencing credibility on the Web. Journal of the American society for information science and technology, 53 (2), pp. 131-145. 